\title{
GMR
}

\section{Comparison between different selection indices in energy cane breeding}

\author{
A.A.C. de Azeredo ${ }^{1}$, L.L. Bhering ${ }^{1}$, B.P. Brasileiro ${ }^{2}$, C.D. Cruz ${ }^{1}$, \\ L.C.I. Silveira ${ }^{3}$, R.A. Oliveira ${ }^{2}$, J.C. Bespalhok Filho² and E. Daros ${ }^{2}$ \\ ${ }^{1}$ Departamento de Biologia Geral, Universidade Federal de Viçosa, MG, Brasil \\ ${ }^{2}$ Departamento de Fitotecnia e Fitossanitarismo, Universidade Federal do Paraná, \\ Curitiba, PR, Brasil \\ ${ }^{3}$ Departamento de Fitotecnia, Universidade Federal de Viçosa, Viçosa, MG, Brasil \\ Corresponding author: A.A.C. de Azeredo \\ E-mail: afonso@agronomo.eng.br \\ Genet. Mol. Res. 16 (1): gmr16019535 \\ Received November 11, 2016 \\ Accepted December 16, 2016 \\ Published March 15, 2017 \\ DOI http://dx.doi.org/10.4238/gmr16019535
}

Copyright (C) 2017 The Authors. This is an open-access article distributed under the terms of the Creative Commons Attribution ShareAlike (CC BY-SA) 4.0 License.

\begin{abstract}
Sugarcane breeding programs have been adapting to a new market demand: aside from high sucrose yield per hectare, the sector needs new cultivars with higher fiber percentages. The selection of sugarcane clones based on phenotype alone is a complex task. The selected clones should display high performance in a series of yieldand quality-related traits. Selection indices can provide information about which clones can best combine the traits of agronomic interest. In this study, different selection indices were evaluated in a population of 220 clones. The following traits were evaluated: weight of 10 stalks with straw, weight of 10 stalks with no straw, tons of cane per hectare with straw, tons of cane per hectare with no straw, sucrose content, fiber percentage, and tons of fiber per hectare. The selection indices of Smith (1936) and Hazel (1943) and Mulamba and Mock (1978), the base index (Williams, 1962), and the index of Pesek and Baker (1969) were used. The selection index of Mulamba and Mock (1978) without economic weight estimates, the index of Mulamba and Mock
\end{abstract}

Genetics and Molecular Research 16 (1): gmr16019535 
with economic weights based on heritability, and the index of Pesek and Baker (1969) with the desired gains based on genetic standard deviations were efficient for the selection of energy cane clones with good fiber yield, sucrose content, and tons of cane per hectare.

Key words: Bioenergy; Second-generation ethanol; Biomass; Fiber; Quantitative genetics; Saccharum spp

\section{INTRODUCTION}

In the search for technologies with lower environmental impact and the growing demand for new sources of renewable fuels, sugarcane is considered the most important raw material for bioenergy production (Matsuoka et al., 2014).

The commercial potential for the production of biofuels derived from sugarcane can be increased 40 to $50 \%$ by the inclusion of lignocellulose bagasse in the production of secondgeneration ethanol (Waclawovsky et al., 2010; Dias et al., 2012). With this production increase, second-generation ethanol has become a promising alternative for overcoming challenges such as high production costs and acreage limitation (Santos et al., 2016).

According to Bull and Glasziou (1963), species of the genus Saccharum have the following descending order of fiber accumulation: S. robustum, S. spontaneum, S. sienese, and $S$. officinarum. The same authors noted that the lower the fiber content, the higher was the sucrose content, since sucrose accumulation was favored during the selection process of the Saccharum complex. Of all studied species, S. spontaneum and S. officinarum contributed most to the development of varieties for sugar production (D'Hont et al., 1995).

The sugarcane clones obtained in the breeding program were classified by Tew and Cobill (2008) into three ideotypes: conventional sugarcane, with approximately $13 \%$ sugar and $12 \%$ fiber content; energy cane type I, with equal to or slightly lower sugar content but higher fiber content (17\%) than conventional sugarcane; and energy cane type II, with low sugar yield (5\%) and high fiber content (30\%).

Since selection for energy cane involves the simultaneous evaluation of different agronomic traits, the traits of fiber content, sugar production, and cane per hectare must be associated with a single value to facilitate decision making for breeders during the selection process. In this sense, the selection indices establish a numerical value, serving as an extra theoretical parameter in order to combine the traits of interest (Cruz et al., 2012). This enables the selection of genotypes that simultaneously combine a number of desirable traits (Miranda et al., 2015).

One of the first indices for plant breeding was proposed by Smith (Smith, 1936), and subsequently adapted for animal breeding by Hazel (Hazel, 1943). The Smith-Hazel index, also known as classical selection index, conditions the determination of the economic value of each trait, as well as the genotypic and phenotypic variances and covariances for each pair of traits (Smith, 1936; Hazel, 1943).

Over the course of time, several researchers have suggested modifications to the classical index. The weighting of the phenotypic values by their respective economical weights was proposed by Williams (1962) in order to avoid inaccuracies associated with the variance and covariance matrices. Pesek and Baker (1969) suggested the replacement of economic weights by the desired gains for traits of interest. For the index of Mulamba and Mock (1978),

Genetics and Molecular Research 16 (1): gmr16019535 
no economic weights or estimates of variance and covariance matrices need to be established, although economic weights can be assigned for a better distribution of selection gains among traits.

Several studies in the literature have analyzed conventional sugarcane selection indices (Pillai and Ethirajan, 1993; Pedrozo et al., 2009; Almeida et al., 2014), although to date, the viability of these indices for the selection of energy cane clones has not been corroborated.

The purpose of this study was to evaluate the feasibility of different indices for the selection of energy cane type I clones to contribute to the choice of the best selection strategy for sugarcane breeding programs.

\section{MATERIAL AND METHODS}

\section{Plant material}

The breeding program of the Inter-University Network for the Development of Sugarcane Industry (RIDESA) has invested efforts in the development of energy cane cultivars, continuing with the selection of 50 full-sib families derived from crosses between $S$. spontaneum and S. robustum accessions, the República Brasil cultivars (RB), and cultivars from other breeding programs.

At the end of the first selection cycle (phase T1), 220 clones were forwarded to the following cycle, where 199 were selected from the 22 best families (crosses) and 21 from 17 other families by mass selection. The 220 clones formed the first generation of clonal selection and were evaluated in the second test phase (T2). The experiment with these 220 clones was carried out at an experimental station of the Federal University of Paraná, in the city of Paranavaí, Paraná, Brazil.

The experiment was arranged in an incomplete block consisting of 39 full-sib families. Each of the 10 blocks consisted of 22 different clones, and the experimental plots consisted of two 5 -m rows (1.4 m between rows) in which 18 buds per meter were planted.

\section{Phenotypic evaluation}

The following traits were evaluated: number of cane stalks (NS), counting all clumps per plot; weight of 10 stalks with no straw (W10Sns; in kg), by weighing 10 stalks per plot with no straw and tips; and weight of 10 stalks with straw (W10Sws; in kg), by weighing 10 randomly collected stalks per plot.

From a sample of five strawless stalks per plot, the fiber percentage (FIB) and percentage of sucrose content (SC) were determined at a sugar mill, according to the technical standards for evaluation of the sugar cane quality established by Conselho de Produtores de Cana-de-Açúcar e Álcool do Estado de São Paulo (CONSECANA, 2006). (TCHns) as

Based on the results, we estimated the traits tons of cane per hectare with no straw

$$
T C H n s=((C W 10 n s / 10) x N S x(10000 / 7)) / 1000 \quad \text { (Equation 1) }
$$

tons of cane per hectare with straw (TCHws) as

Genetics and Molecular Research 16 (1): gmr16019535 


$$
T C H w s=((C W 10 c p / 10) x N S x(10000 / 7)) / 1000 \quad(\text { Equation } 2)
$$

and tons of fiber of cane with straw per hectare (TFHws) as

$$
T F H w s=(T C H w s x F I B) / 100
$$

\section{Statistical analysis}

The variance components and breeding values were estimated by the procedure of restricted maximum likelihood/best linear unbiased prediction (REML/BLUP), according to the adjusted model:

$$
y=X r+Z f+W b+S c+e
$$

where $y$ is the data vector; $r$ is the vector of fixed effects (replication) added to the general mean; $f$ is the vector of the effects of full-sib families (random); $b$ is the vector of effects of incomplete blocks (random); $c$ is the vector of clone effects within the full-sib family (random); and $e$ is the error or residue vector (random). The capital letters (X, Z, W, and $\mathrm{S}$ ) represent the incidence matrices for the effects of $\mathrm{r}, \mathrm{f}, \mathrm{b}$, and $\mathrm{c}$, respectively. For this analysis, we used model 182 of the Selegen-REML/BLUP (Resende, 2007) software.

The broad-sense heritability $\left(h_{g}^{2}\right)$ is given by:

$$
h_{g}^{2}=\frac{\sigma_{f a m}^{2}+\sigma_{c l o / f a m}^{2}}{\sigma_{f}^{2}}
$$

where $\sigma_{\text {fam }}^{2}$ is the total variance between full-sib families; $\sigma_{c l o / f a m}^{2}$ is the variance of clones within full-sib families; and $\sigma_{f}^{2}$ is the phenotypic variance.

\section{Selection strategies}

The applied selection indices were: Smith (1936) and Hazel (1943), Mulamba and Mock (1978), the basic index (Williams, 1962), and Pesek and Baker (1969).

The indices of Smith (1936) and Hazel (1943), Mulamba and Mock (1978), and Williams (1962) were used without assigning economic weight, although equal weights including the genetic standard deviation (GSD), coefficient of genetic variation (CGV), and broad-sense heritability $(\mathrm{H})$ were also assigned.

Another economic weight applied was the trait of highest mean in the index, such as a numerator of the ratio of the other traits, including the trait itself (PROP), so that the trait with the highest mean has a weight of 1 and the weight with the lowest mean has a weight higher than 1 . Therefore, if the order of the means of the three traits is $X 1>X 2>X 3$, the weight for each trait will be the result of the ratios $X 1 / X 1, X 1 / X 2$, and $X 1 / X 3$, respectively.

The above economic weights were used as desired gains for the Pesek-Baker index (1969), to which gains equal to 1 (W1) were also attributed. Direct selection was applied (DS)

Genetics and Molecular Research 16 (1): gmr16019535 
for each trait, considering the mean increase. For all strategies, the applied selection rate was $10 \%$ ( 22 clones).

Software Genes was used for all selection strategies (Cruz, 2013). The correlation estimates between genotypic values and coincidence rate were carried out with $\mathrm{R}$ software $(\mathrm{R}$ Development Core Team, 2015). To improve visualization of the relationships between the clones selected by the different selection strategies, a network graph was built using Gephi open source software (Bastian, et al., 2009).

\section{RESULTS AND DISCUSSION}

The deviance analysis indicated a significant effect of genotypic variance for all studied traits, suggesting the presence of genetic variability in the clonal population (Table 1).

Table 1. Estimation of variance components and genetic parameters for the following traits: weight of 10 stalks with straw (W10Sws), weight of 10 stalks with no straw (W10Sns), tons of cane per hectare with straw (TCHws), tons of cane per hectare with no straw (TCHns), sucrose content (SC), fiber percentage (FIB), and tons of fiber per hectare (TFHws).

\begin{tabular}{l|c|c|c|c|c|c|c}
\hline Parameters $^{1}$ & W10Sws (kg) & W10Sns (kg) & TCHws (Mg/ha) & TCHns (Mg/ha) & SC (\%) & FIB (\%) & TFHws (Mg/ha) \\
\hline$\sigma_{\text {fam }}^{2}$ & 6.73 & 5.7 & 458.22 & 423.83 & 1.74 & 0.84 & 8.37 \\
\hline$\sigma_{b l}^{2}$ & 0.04 & 0.18 & 2.18 & 28.25 & 0.05 & 0.01 & 0.06 \\
\hline$\sigma_{c l / / \text { amm }}^{2}$ & 1.5 & 1.05 & 185.83 & 125.6 & 0.32 & 0.26 & 3.7 \\
\hline$\sigma_{g}^{2}$ & $8.23^{*}$ & $6.75^{*}$ & $644.05^{*}$ & $549.43^{*}$ & $2.06^{*}$ & $1.10^{*}$ & $12.07^{*}$ \\
\hline$\sigma_{e}^{2}$ & 10.77 & 7.66 & 1307.0 & 903.4 & 2.35 & 1.84 & 25.97 \\
\hline$\sigma_{f}^{2}$ & 19.04 & 14.6 & 1953.24 & 1481.08 & 4.46 & 2.94 & 38.1 \\
\hline$h_{\text {fam }}^{2}$ & $0.35 \pm 0.11$ & $0.39 \pm 0.12$ & $0.23 \pm 0.09$ & $0.29 \pm 0.1$ & $0.39 \pm 0.12$ & $0.29 \pm 0.1$ & $0.22 \pm 0.09$ \\
\hline$h_{g}^{2}$ & 0.43 & 0.46 & 0.33 & 0.37 & 0.46 & 0.37 & 0.32 \\
\hline$A C_{g e n}$ & 0.66 & 0.66 & 0.73 & 0.76 & 0.65 & 0.69 & 0.75 \\
\hline$C v_{g i}$ & 18.71 & 22.79 & 13.54 & 17.32 & 14.51 & 6.43 & 12.96 \\
\hline$C v_{e}$ & 23.67 & 26.41 & 22.87 & 25.29 & 16.9 & 9.51 & 22.82 \\
\hline Mean & 13.87 & 10.48 & 158.1 & 118.85 & 9.08 & 14.24 & 22.33 \\
\hline
\end{tabular}

${ }^{1}$ Variance between families $\left(\sigma_{\text {fam }}^{2}\right)$, variance between blocks $\left(\sigma_{b l}^{2}\right)$, variance of clones within families $\left(\sigma_{c l o / f a m}^{2}\right)$, environmental variance $\left(\sigma_{e}^{2}\right)$, individual phenotypic variance $\left(\sigma_{f}^{2}\right)$, mean family heritability $\left(h_{\text {fam }}^{2}\right)$, broad-sense heritability $\left(h_{g}^{2}\right)$, genetic accuracy $\left(A C_{g e n}\right)$, coefficient of genetic variation $\left(C v_{g i}\right)$, coefficient of environmental variation $\left(C v_{e}\right)$, and overall mean (mean). * Significant at $5 \%$ probability according to the deviance analysis.

The accuracies were moderate to high, varying from 65 to $76 \%$, which indicates a good correlation between the predicted genotypic mean and the real values of plants, enabling genetic gains by clonal selection (Resende and Duarte, 2007) (Table 1).

The broad-sense heritability estimates ranged from 0.33 to 0.46 , respectively, for TCHns and SC (Table 1); values considered average by Resende (2002). Broad-sense heritability is an important parameter; when the variability from the initial cross is exploited, its magnitude is directly related to the possible selection gains in the different phases of the program (Zhou and Joshi, 2012). The environmental variation coefficients for the seven 
evaluated traits varied from 9.51 to $26.41 \%$, which is considered low to medium according to Pimentel-Gomes (2009), indicating good experimental precision (Table 1).

The correlation between genotypic values was high for W10ws and W10ns $\left(\mathrm{r}_{\mathrm{vg}}=\right.$ 0.95), indicating a high degree of statistical linear association between the two traits (Figure 1). According to Dancy and Reidy (2011), the intensity of the correlation coefficients, positive or negative, can be classified roughly as: zero (0), weak (0.1-0.3), moderate (0.4-0.6), strong (0.7-0.9), or perfect (1). Since the weights of 10 stalks with and without straw were multiplied by the same number of stalks to estimate tons of cane per hectare with and without straw, respectively, a strong linear association between the two traits $\left(r_{v g}=0.95\right)$ was expected (Figure 1).

The trait TFHws is strongly correlated with the genotypic values TCHws $\left(r_{v g}=0.89\right)$ and TCHns $\left(\mathrm{r}_{\mathrm{vg}}=0.79\right)$ (Figure 1). If we generalize the results of this experiment in order to optimize the collection of field data, the stalk weight with and without straw becomes unnecessary, and only one trait should be chosen to reduce the cost of phenotyping.

The traits SC and FIB were weakly correlated with each other, and had weak to moderate correlation with the other five traits (Figure 1). According to Ramdoyal and Badaloo (2007), despite a negative or weak correlation between sucrose and fiber content, which may be due to pleiotropic genes or genetic linkage, it is possible to select clones with an acceptable percentage of sucrose content and high fiber content.

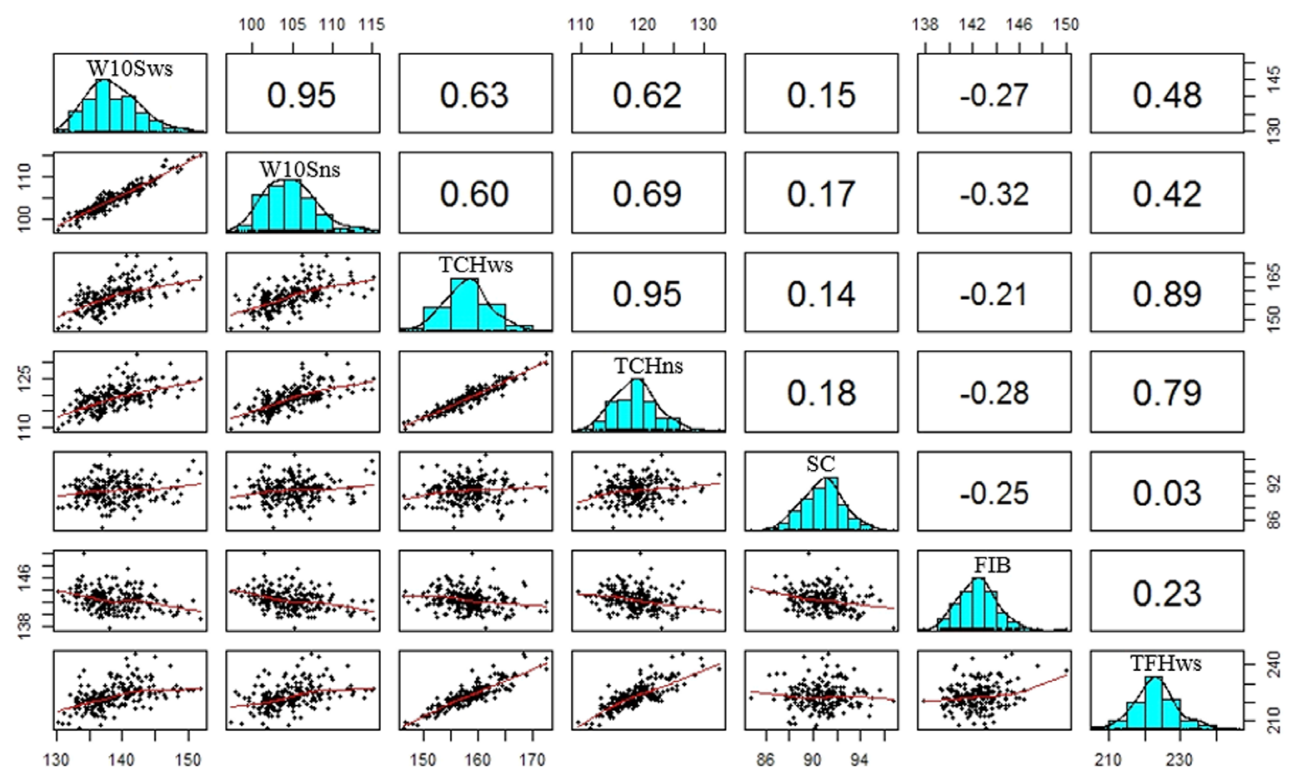

Figure 1. Correlation between genotypic values $(u+g)\left(\mathrm{r}_{\mathrm{vg}}\right)$ between the following traits: weight of 10 stalks with straw (W10Sws), weight of 10 stalks with no straw (W10Sns), tons of cane per hectare with straw (TCHws), tons of cane per hectare with no straw (TCHns), sucrose content (SC), fiber percentage (FIB), and tons of fiber per hectare with straw (TFHws). On the main diagonal are histograms of distribution; at the top of the matrix are the correlation coefficients between genotypic values; and on the lower diagonal is the graphical dispersion and regression line.

Genetics and Molecular Research 16 (1): gmr16019535 
In view of the strong correlation of TCHns with the other traits, except for FIB and $\mathrm{SC}$, these three traits were chosen to underlie the indices presented in Table 2.

In the direct selections (DS), the selection for SC obtained the highest total sum of gain per selection $(22.13 \%)$, occupying the sixth position, and the selection gain for TCHns was $18.47 \%$ (Table 2). The direct selection for SC resulted in a positive indirect gain for TCHns (6.16\%), although the indirect gain for FIB was practically zero $(-2.5 \%)$ (Table 2$)$.

\begin{tabular}{|c|c|c|c|c|c|}
\hline \multirow[t]{2}{*}{ Selection } & TCHns & $\mathrm{SC}$ & FIB & Sum & \multirow[t]{2}{*}{ Rank } \\
\hline & \multicolumn{4}{|c|}{ SG(\%) } & \\
\hline WI.PROP $^{1}$ & 17.15 & 12.22 & -0.34 & 29.03 & 1 \\
\hline SH.PROP & 16.14 & 14.94 & -2.4 & 28.68 & 2 \\
\hline SH.H & 21.68 & 4.44 & -2.56 & 23.56 & 3 \\
\hline MM.GSD & 22 & 2.99 & -2.4 & 22.59 & 4 \\
\hline SH & 22 & 2.99 & -2.4 & 22.59 & 5 \\
\hline DS.SC & 6.16 & 18.47 & -2.5 & 22.13 & 6 \\
\hline MM.H & 7.31 & 11.06 & 3.7 & 22.07 & 7 \\
\hline MM & 8.93 & 8.63 & 4.26 & 21.82 & 8 \\
\hline SH.CGV & 22.18 & 1.94 & -2.75 & 21.37 & 9 \\
\hline WI.CGV & 22.26 & 1.05 & -2.53 & 20.78 & 10 \\
\hline WI.H & 22.26 & 1.05 & -2.53 & 20.78 & 11 \\
\hline WI & 22.26 & 1.05 & -2.53 & 20.78 & 12 \\
\hline PB.GSD & 10.38 & 4.54 & 5.83 & 20.75 & 13 \\
\hline SH.GSD & 22.18 & 1.68 & -3.11 & 20.75 & 14 \\
\hline DS.TCHns & 22.27 & 0.63 & -2.62 & 20.28 & 15 \\
\hline WI.GSD & 22.27 & 0.63 & -2.62 & 20.28 & 16 \\
\hline MM.PROP & 1.55 & 11.22 & 4.47 & 17.24 & 17 \\
\hline PB.CGV & -0.52 & 8.68 & 6.33 & 14.49 & 18 \\
\hline PB.H & 0.15 & 3.59 & 7.91 & 11.65 & 19 \\
\hline PB.W1 & 0.15 & 3.59 & 7.91 & 11.65 & 20 \\
\hline PB.PROP & -1.86 & 5.47 & 7.47 & 11.08 & 21 \\
\hline DS.FIB & -3.17 & -3.9 & 8.66 & 1.59 & 22 \\
\hline MM.CGV & -16.56 & -15.03 & 3.19 & -28.4 & 23 \\
\hline
\end{tabular}

${ }^{1}$ Direct selection (DS), Smith and Hazel (SH), Mulamba and Mock (MM), Williams (WI), Pesek and Baker (PB). Weights/desired gains equal to: genetic standard deviation (GSD); coefficient of genetic variation (CGV), weight = 1 (W1), broad-sense heritability $(\mathrm{H})$, and ratio of the highest mean (PROP).

The second-best performance in the sum of direct selection was obtained for TCHns (20.28), while the percentage of selection gain for TCHns was the highest $(22.27 \%)$ of the three agronomic traits studied in the three direct selections (Table 2). With the direct selection for TCHns, the gain by indirect selection was practically zero $(0.63 \%)$ for SC and negative for FIB (-2.62\%) (Table 2).

The summary of the direct selection gains for FIB had the worst performance, ranking second-to-last of all sums of selection gains (1.59\%) with a selection gain for FIB of $8.66 \%$ (Table 2). The indirect selection gains for FIB were negative for TCHns $(-3.17 \%)$ and SC $(-3.9 \%)$ (Table 2).

For comparison of the selection gains obtained by all tested indices, it is important to observe, primarily, the direct selection for each trait. In direct selection, the maximum amount of direct gain for each trait is known, so the ideal index for simultaneous selection must combine the closest possible gains of the direct gains from the direct selections (Table 2).

In Table 2, the six best-ranked selection strategies allowed gains for TCHns and SC. However, these strategies also induced negative or low gains for FIB (-2.9 to $-0.34 \%)$. For 
selection strategies 9 to 16 (ranking shown in Table 2), with the exception of 13, the gains of all were high only for TCHns (22.18-22.27\%). Strategies 17 to 21 induced gains for the traits SC (3.59-11.22\%) and FIB (4.47-7.47\%) (Table 2).

According to Silveira et al. (2015a), selection for fiber content in energy cane families cannot be efficient if the levels of tons of cane per hectare are low, and in the selection for energy cane type I, the sugar content should also be maintained at the level of a conventional cultivar.

The selection gains obtained for the traits SC, FIB, and TCHns using the indices of Mulamba and Mock without estimated weights, Mulamba and Mock with economic weights equal to heritability, and Pesek-Baker with desired gains equal to the standard genetic deviation were better distributed (Table 2), and these are therefore the recommended indices for selection of energy cane type I.

The relationship between the clones selected by the selection strategies examined in this study can be observed by the coefficient of coincidence (CC) in the representation in Figure 2, where the greater the circumference and the closer to the dark blue color, the higher the relationship (Figure 2). The indices WI.PROP and SH.PROP $(\mathrm{CC}>0.8)$ obtained simultaneous gains for TCHns and SC (Table 2). Under the indices MM.GSD, SH.H, SH, SH.CGV, WI.CGV, WI.H, WI, SH.GSD, SD.THCns, and WI.GSD, the coincidence between the selected clones was high $(\mathrm{CC}>0.9)$ (Figure 2). These indices provided high gains for TCHns (Table 2).

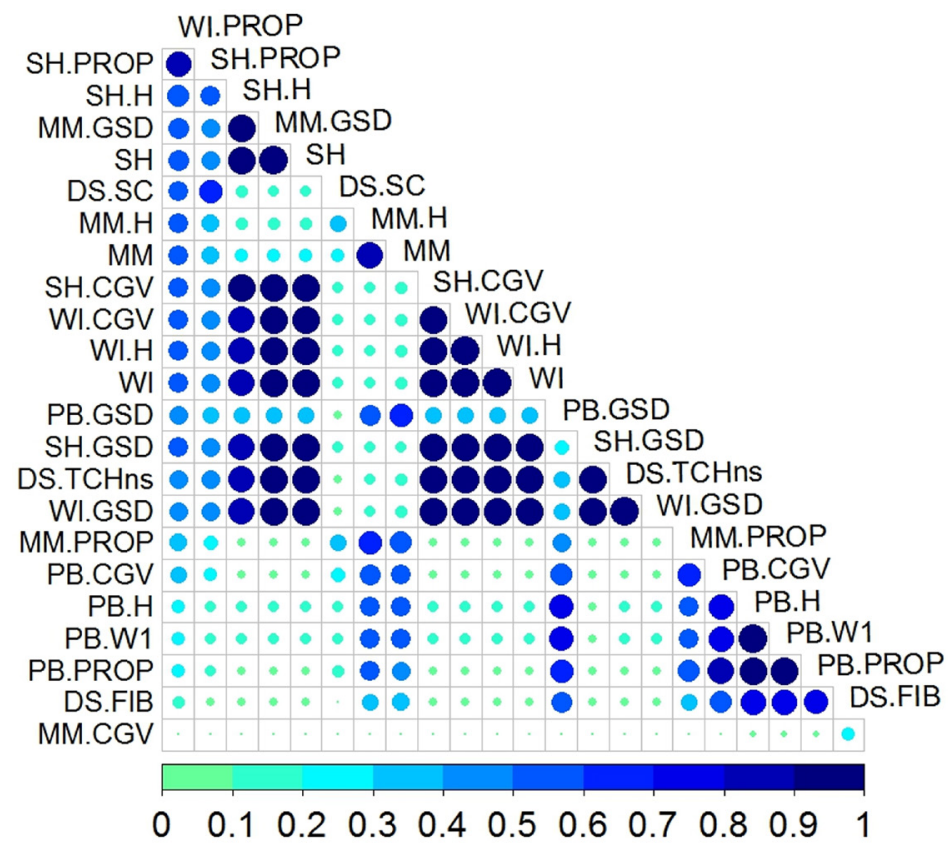

Figure 2. Coincidence coefficient (CC) for the clones selected by the following strategies: Direct Selection (DS), Smith and Hazel (SH), Mulamba and Mock (MM), Williams (WI), and Pesek and Baker (PB). Weights/desired gains equal to: genetic standard deviation $(\mathrm{GSD})$; genetic variation coefficient $(\mathrm{CGV})$, weight $=1$ (W1), broadsense heritability $(\mathrm{H})$, and ratio of the highest mean (PROP) at a selection rate of $10 \%$. 
For the clones selected above 0.59 , the results obtained by the indices PB.CGV, PB.H, PB.W1, PB, PB.PROP, and DS.FIB were coincident and indicated good performance for FIB (Figure 2 and Table 2). For most of the tested indices, those that were ranked near each other selected a higher number of equal clones.

Among the direct selections, the coincidence between the selected clones was low, which was expected in view of the low genotypic correlation coefficients for the traits FIB, $\mathrm{SC}$, and TCHns (Figures 1 and 2). The most balanced distribution of selection gains for FIB, $\mathrm{SC}$, and TCHns was obtained by indices MM.H and MM, with a high coincidence between the selected clones (0.86), although the mean percentage of coincidence with PB.DPG of these two indices was 0.56 and 0.64 , respectively (Table 2 and Figure 2). In view of the gains by the three indices in all three traits and although a few different clones were selected, it would be interesting to use all selected clones in the following stages of the program.

Although few clones were selected simultaneously in the three direct selections, of the 32 different clones selected by the three selection indices with most balanced distribution, 24 were also selected by the direct selections (Figure 3). Of the 49 full-sib families evaluated in this experiment, 18 were represented, with 32 selected clones (Figure 3).

The clones PRBIO53 and PRBIO143 were advanced to the next cycle based on direct selections for TCHns and FIB and for the indices of Mulamba and Mock without estimated weight, Mulamba and Mock with weight based on heritability, and Pesek and Baker with gains based on the genetic standard deviation (Figure 3).

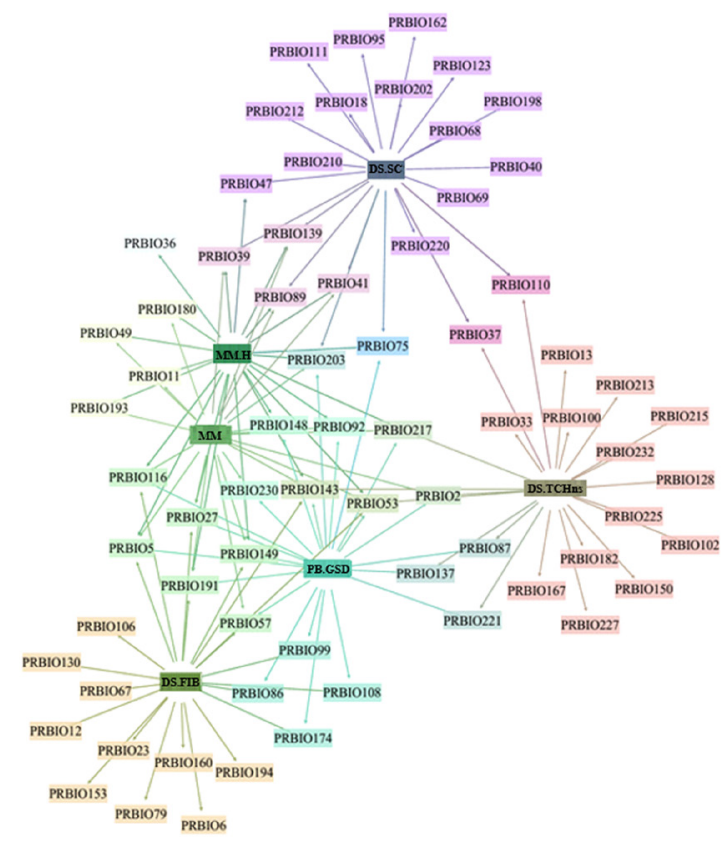

Figure 3. Network diagram of the relationship between the clones selected by direct selection for tons of cane per hectare with no straw (DS.TCHns), sucrose content (DS.SC), and fiber percentage (DS.FIB) and the indices of Mulamba and Mock without estimated weight (MM), with economic weight equal to heritability (MM.H), and Pesek and Baker with the desired gains equal to the genetic standard deviation (PB.GSD), at a selection rate of $10 \%$ for each index for energy cane clones.

Genetics and Molecular Research 16 (1): gmr16019535 
The 32 clones were selected by direct selection and by the three selection indices with the most balanced selection gains (Figure 3 ). None of the clones selected by direct selection for FIB was selected by direct selection for SC (Figure 3). The clones PRBIO110 and PRBIO37 were selected coincidentally by direct selection for SC and TCHns, but were not selected by any index due to the low percentage of FIB (@11\%) (Figures 3 and 4).

It was possible to detect individual clones with good overall performance, such as PRBIO203 (13\% SC, 140.63 TCHns, and 16.28\% FIB), PRBIO116 (11\% CP, 17.65\% FIB, and 127.39 TCHns), and PRBIO148 (11\% CP, 16.27\% FIB, and 122.65 TCHns) (Figure 4). According to Silveira et al. (2015b), cultivars of energy cane type 1 with sucrose contents maintained at levels around $13 \%$ and fiber contents around $17 \%$ would be able to meet the current demands of the sugarcane industry (Figure 4).

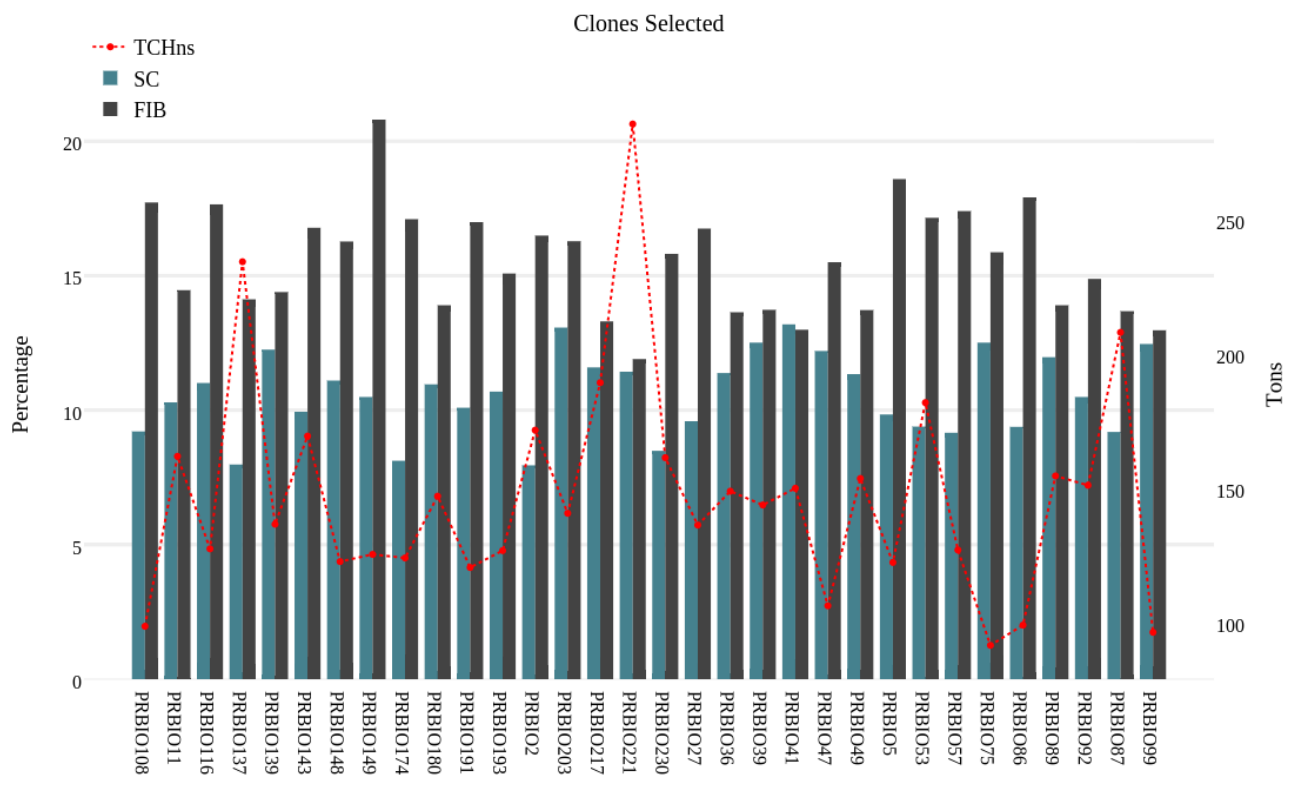

Figure 4. Performance of 32 sugarcane clones selected by the indices of Mulamba and Mock without estimated economic weight, Mulamba and Mock with economic weight equal to the heritability, and Pesek-Baker with expected gain based on genetic standard deviation for sucrose content percentage (SC), fiber percentage (FIB), and tons of cane per hectare with no straw (TCHns).

Although 32 clones were selected, it is important to note that as reported by Lucius et al. (2014), mass selection can eliminate clones selected by the indices, as some clones may have disease symptoms and/or other undesirable traits such as physiological pith flowering, susceptibility to pests, lodging, or excessively protruding buds; i.e., if necessary, some previously selected clones can be eliminated. Another important factor is that when a particular index is chosen, the selection efficiency as well as the estimated heritability depends on the population to be improved (Pedrozo et al., 2009).

During the subsequent selection phases, genetic parameter estimates become more accurate because the clones are being evaluated with replications and at several locations. If the observed behaviors are confirmed, not only the possible cultivars of energy cane type I but 
also the 32 clones selected by the indices of Mulamba and Mock without estimated economic weight, Mulamba and Mock with economic weight based on heritability, and the Pesek-Baker index with desired gains based on genetic standard deviation must be crossed with each other to search for promising energy cane clones in new selection cycles. When selecting these same clones in the previous cycle (T1 phase), Silveira et al. (2015b) emphasized the need to cross different clones and the use of reciprocal recurrent selection (RRS) for successful development of new varieties of energy cane type I and II.

Of the 32 selected clones, only PRBIO41 had a higher sucrose $(\mathrm{SC}=13.19 \%)$ than fiber content ( $\mathrm{FIB}=12.99 \%$ ) (Figure 4). If the breeding target is the development of varieties with even higher fiber contents (FIB), a useful strategy could be the selfing of clones, because de Azeredo et al. (2016) found a higher mean FIB in sugarcane progenies resulting from selfing (S1) than in their parents. These authors recommended that in addition to direct selection, the clones could be subjected to a scheme of reciprocal individual recurrent selection of selfed progenies (RRS-S1) to obtain varieties with higher fiber production.

\section{CONCLUSION}

The selection indices of Mulamba and Mock without estimation of the economic weight, Mulamba and Mock with heritability-based economic weights, and Pesek and Baker with desired genetic gains based on the genetic standard deviation proved efficient for the selection of energy cane type I clones.

\section{Conflicts of interest}

The authors declare no conflict of interest.

\section{ACKNOWLEDGMENTS}

The authors are indebted to Coordenação de Aperfeiçoamento de Pessoal de Nível Superior (CAPES), Conselho Nacional de Desenvolvimento Científico e Tecnológico (CNPq), Fundação Arthur Bernardes (Funarbe), Fundação de Amparo à Pesquisa do Estado de Minas Gerais (FAPEMIG), Foundation of the Federal University of Paraná (Funpar), sugarcane breeding program of the Federal University of Paraná/Inter-University Network for the Development of Sugarcane Industry-PMGCA/UFPR/RIDESA, and to the laboratories of Bioinformatics and Biometry of Universidade Federal de Viçosa-UFV.

\section{REFERENCES}

Almeida LM, Viana AP, Amaral Júnior ATD, Júnior C, et al. (2014). Breeding full-sib families of sugar cane using selection index. Cienc. Rural 44: 605-611. http://dx.doi.org/10.1590/S0103-84782014000400005

de Azeredo AA, Bhering LL, Brasileiro BP, Cruz CD, et al. (2016). Selection in sugarcane based on inbreeding depression. Genet. Mol. Res. 15: 1-11. http://dx.doi.org/10.4238/gmr.15027965

Bastian M, Heymann S and Jacomy M (2009). Gephi: An open source software for exploring and manipulating networks. Proc. Third Int. ICWSM Conf. 8: 361-362.

Bull TA and Glasziou KT (1963). The evolutionary significance of sugar accumulation in Saccharum. Aust. J. Biol. Sci. 16: 737-742. http://dx.doi.org/10.1071/BI9630737

Conselho Dos Produtores de Cana-de-açúcar e Álcool do Estado de São Paulo (CONSECANA) (2006). Manual de

Genetics and Molecular Research 16 (1): gmr16019535 
Instruções, Piracicaba.

Cruz CD, Regazzi AJ and Carneiro PCS (2012). Modelos Biométricos Aplicados ao Melhoramento Genético. Vol. 1. Editora UFV, Viçosa.

Cruz CD (2013). Genes: a software package for analysis in experimental statistics and quantitative genetics. Acta Sci. Agron. 35: 271-276. http://dx.doi.org/10.4025/actasciagron.v35i3.21251

D'Hont A, Grivet L, Feldmann P, Rao S, et al. (1996). Characterisation of the double genome structure of modern sugarcane cultivars (Saccharum spp.) by molecular cytogenetics. Mol. Gen. Genet. 250: 405-413. http://dx.doi. org/10.1007/BF02174028

Dancy CP and Reidy J (2011). Statistics without Maths for Psychology. 6th edn. Harlow, England.

Dias MO, Junqueira TL, Cavalett O, Cunha MP, et al. (2012). Integrated versus stand-alone second generation ethanol production from sugarcane bagasse and trash. Bioresour. Technol. 103: 152-161. http://dx.doi.org/10.1016/j. biortech.2011.09.120

Hazel LN (1943). The genetic basis for constructing selection indexes. Genetics 28: 476-490.

Lucius ASF, Oliveira RA, Daros E, Bespalhok Filho JC, et al. (2014). Desempenho de famílias de cana-de-açúcar em diferentes fases no melhoramento genético via REML/BLUP. Semin. Cienc. Agrar. 35: 101-112. http://dx.doi. org/10.5433/1679-0359.2014v35n1p101

Matsuoka S, Kennedy AJ, Santos EGDD, Tomazela AL, et al. (2014). Energy cane: its concept, development, characteristics, and prospects. Adv. Botany 2014: 1-13. http://dx.doi.org/10.1155/2014/597275

Miranda AC, De Moraes MLT, Da Silva PHM and Sebbenn AM (2015). Genetic gain in the selection by multi-effects index in open-pollinated progenies of Eucalyptus grandis Hill ex Maiden. Sci. Forum 45: 203-209.

Mulamba NN and Mock JJ (1978). Improvement of yield potential of the Eto Blanco maize (Zea mays L.) population by breeding for plant traits. Egypt. J. Genet. Cytol. 7: 40-51.

Pedrozo CA, Benites FRG, Barbosa MHP, DE Resende MDV, et al. (2009). Eficiência de índices de seleção utilizando a metodologia REML/BLUP no melhoramento da cana-de-açúcar. Sci. Agric. 10: 31-36.

Pesek J and Baker RJ (1969). Desired improvement in relation to selection indices. Can. J. Plant Sci. 1: 215-274.

Pillai SV and Ethirajan AS (1993). Selection indices for sugarcane improvement at three stages of selection. Euphytica 71: 155-159. http://dx.doi.org/10.1007/BF00023479

Pimentel-Gomes F (2009). Curso de estatística experimental. $15^{\text {th }}$ edn. FEALQ, Piracicaba.

R DEVELOPMENT CORE TEAM (2015). R: A language and environment for statistical computing. R Foundation for Statistical Computing, Vienna, Austria.

Ramdoyal K and Badaloo M (2007). An evaluation of interspecific families of different nobilized groups in contrasting environments for breeding novel sugarcane clones for biomass. Int. Soc. Sugar Cane Technol. 625-637.

Resende MDV (2002). Genética Biométrica e Estatística no Melhoramento de Plantas Perenes. Embrapa Informação Tecnológica. Colombo: Embrapa Florestas, Brasília.

Resende MDV (2007). Selegen-Reml/Blup: sistema estatístico e seleção genética computadorizada via modelos lineares mistos. Colombo: Embrapa Florestas.

Resende MDV and Duarte JB (2007). Precisão e controle experimental de qualidade em experimentos de avaliação de cultivares. Pesqui. Agropecu. Trop. 37: 182-194.

Santos LV, Barros GMC, Gallardo JCM, Pirolla RAS, et al. (2016). Second-Generation Ethanol: The Need is Becoming a Reality. Ind. Biotechnol. (New Rochelle N.Y.) 12: 40-57. http://dx.doi.org/10.1089/ind.2015.0017

Silveira LCI, Brasileiro BP, Kist V, Weber H, et al. (2015a). Selection strategy in families of energy cane based on biomass production and quality traits. Euphytica 204: 443-455. http://dx.doi.org/10.1007/s10681-015-1364-9

Silveira LCI, Brasileiro BP, Kist V, Daros E, et al. (2015b). Genetic diversity and coefficient of kinship among potential genitors for obtaining cultivars of energy cane. Rev. Cienc. Agron. 46: 358-368b.

Smith HF (1936). A discriminant function for plant selection. Ann. Eugen. 7: 240-250. http://dx.doi. org/10.1111/j.1469-1809.1936.tb02143.x

Tew TL and Cobill RM (2008). Genetic improvement of sugarcane (Saccharum spp.) as an energy crop. In: Genetic improvement of bioenergy crops (Vermerris W). Springer New York, 273-294.

Waclawovsky AJ, Sato PM, Lembke CG, Moore PH, et al. (2010). Sugarcane for bioenergy production: an assessment of yield and regulation of sucrose content. Plant Biotechnol. J. 8: 263-276. http://dx.doi.org/10.1111/j.14677652.2009.00491.x

Williams JS (1962). The evaluation of a selection index. Biometrics 18: 375-393. http://dx.doi.org/10.2307/2527479

Zhou M and Joshi S (2012). Trends in broad sense heritability and implications for sugarcane breeding in South Africa. Sugar Tech. 14: 40-46. http://dx.doi.org/10.1007/s12355-011-0128-7

Genetics and Molecular Research 16 (1): gmr16019535 